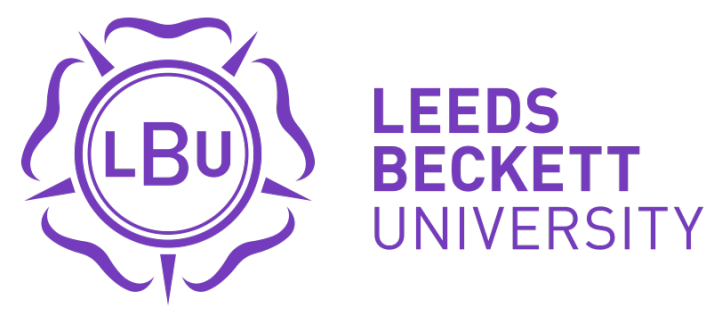

Citation:

Mellor, A and Bakker-Dyos, J and OHara, J and Woods, DR and Holdsworth, DA and Boos, C (2017) Smartphone-Enabled Heart Rate Variability and Acute Mountain Sickness. Clinical Journal of Sport Medicine, 28 (1). pp. 76-81. ISSN 1536-3724 DOI: https://doi.org/10.1097/JSM.0000000000000427

Link to Leeds Beckett Repository record:

https://eprints.leedsbeckett.ac.uk/id/eprint/3798/

Document Version:

Article (Accepted Version)

Creative Commons: Attribution-Noncommercial-No Derivative Works 4.0

The aim of the Leeds Beckett Repository is to provide open access to our research, as required by funder policies and permitted by publishers and copyright law.

The Leeds Beckett repository holds a wide range of publications, each of which has been checked for copyright and the relevant embargo period has been applied by the Research Services team.

We operate on a standard take-down policy. If you are the author or publisher of an output and you would like it removed from the repository, please contact us and we will investigate on a case-by-case basis.

Each thesis in the repository has been cleared where necessary by the author for third party copyright. If you would like a thesis to be removed from the repository or believe there is an issue with copyright, please contact us on openaccess@leedsbeckett.ac.uk and we will investigate on a case-by-case basis. 


\section{Smartphone-enabled Heart Rate Variability and Acute Mountain Sickness}

Adrian Mellor1-3 Josh Bakker-Dyos1, John O’Hara3, David Richard Woods1,3,-5 David A Holdsworth, 1,8 Christopher John Boos3,6,7

1Defence Medical Services, Lichfield, UK

2James Cook University Hospital, Middlesbrough, TS4 3BW, UK

3Research Institute, for Sport, Physical Activity and Leisure, Leeds Beckett

University, Leeds, UK

4Northumbria and Newcastle NHS Trusts, Wansbeck General and Royal Victoria

Infirmary, Newcastle, UK

5 University of Newcastle, Newcastle upon Tyne, UK

6Department of Cardiology, Poole Hospital NHS Foundation trust, Poole, UK

7 Dept of Postgraduate Medical Education, Bournemouth University, Bournemouth, $\mathrm{UK}$

8Dept of Physiology, University of Oxford, UK

Key words high altitude, arrhythmias, heart rate variability, ithelete ${ }^{\mathrm{TM}}$

Corresponding author: Professor Christopher J Boos, Department of Cardiology, Poole Hospital NHS Foundation Trust, Longfleet Rd. Poole, Dorset, BH15 2JB

Tel +44 120244 2572; fax +44 1202442754 email: christopherboos@ hotmail.com 


\section{Introduction}

The autonomic system and sympathetic activation appears integral in the pathogenesis of acute mountain sickness (AMS) at high altitude (HA), yet a link between heart rate variability (HRV) and AMS has not been convincingly shown. In this study we investigated the utility of the smartphone-derived HRV score to predict and diagnose AMS at HA.

\section{Methods}

Twenty one healthy adults were investigated at baseline at $1400 \mathrm{~m}$ and over 10 days during a trek to 5140m. HRV was recorded using the ithleteтм HRV device.

\section{Results}

AMS occurred in 11 subjects $(52.4 \%)$ at $>2650 \mathrm{~m}$. HRV inversely correlated with AMS Scores ( $\mathrm{r}=-0.26$; $95 \%$ CI -0.38 to -0.13 : $\mathrm{p}<0.001)$. HRV significantly fell at $3700 \mathrm{~m}$, $4100 \mathrm{~m}$ and $5140 \mathrm{~m}$ versus low altitude. HRV scores were lower in those with both mild (69.7 \pm 14.0$)$ and severe AMS $(67.1 \pm 13.1)$ versus those without AMS $(77.5 \pm 13.1$; effect size $n_{2}=0.043: \mathrm{p}=0.007$ ). The HRV score was weakly predictive of severe AMS (AUC $0.74 ; 95 \%$ CI 0.58 to 0.89: $\mathrm{p}=0.006$ ). The change (delta) in the HRV Score (compared with baseline at $1400 \mathrm{~m}$ ) was a moderate diagnostic marker of severe AMS (AUC 0.80; 95\% CI 0.70 to 0.90; $\mathrm{p}=0.0004)$. A fall in the HRV score of $>5$ had a sensitivity of $83 \%$ and specificity of $60 \%$ to identify severe AMS (likelihood ratio 1.9). Baseline HRV at 1400m was not predictive of either AMS at higher altitudes.

\section{Conclusions}

The ithlete HRV score can be used to help in the identification of severe AMS, however a baseline score is not predictive of future AMS development at HA 


\section{INTRODUCTION}

High altitude (HA) illness consists of Acute Mountain Sickness (AMS), which is usually a selflimiting collection of symptoms including headache and lethargy, which can lead to? HA Cerebral Edema (HACE) and HA Pulmonary Edema (HAPE). HACE and HAPE are lifethreatening.1The incidence of AMS is dependent on a number of factors which include individual susceptibility, the speed of ascent and altitude attained.2 It is known to affect $>50 \%$ of persons at ascending to an altitude of 5000m.1-4

The mechanism of AMS development is highly complex and is still not fully understood.1 HArelated hypoxia and changing homeostasis triggers a number of well-established physiological responses which include the adrenal medullary release of epinephrine and an increase in whole body and tissue specific sympathetic nerve activity.5 This leads to an increase in metabolic, heart and respiratory rate and changes in cerebral blood flow, that act to counteract the effects of hypobaric hypoxia.5-7 There is accumulating evidence to suggest that the autonomic system and alterations in the sympathetic/parasympathetic balance may play an important pathogenic role in the development of AMS and its susceptibility.7-11

Heart rate variability (HRV) represents an increasingly utilised, yet non- invasive method of assessing autonomic function. HRV is quantified by measuring changes in cardiac beat-to-beat (R-R) intervals which are under continuous autonomic control.12 Conditions that are known to affect the sympathetic/parasympathetic balance such as inter-current illness, cardiovascular disease, physical overtraining ande mental stress have been shown to lead to a reduction in HRV.13-15 Changes in HRV have been demonstrated on ascent to HA and typified by an increase in measures of sympathetic and a decrease in parasympathetic activity.16,17 However, a link between alterations in HRV and AMS development at HA has not been convincingly shown.3,18-21

Traditional methods of HRV measurement have required relatively large and expensive equipment with a need for at least five minutes of electrocardiographic (ECG) recording.22 The ithelte $^{\mathrm{TM}}$ (HRV Fit Ltd, Southampton, UK) system is a recently available method of noninvasive HRV assessment from only 55 seconds of recording obtained via a chest strap or finger sensor linked to a mobile smartphone. The ithelte ${ }^{\mathrm{TM}}$ generates an intuitive 1-100 HRV score which is a logarithmic adaptation of the root mean square of successive R-R intervals (RMSSD) provided by traditional HRV devices.23 It has been shown that the RMSDD, can be derived from shorter recording times and is less prone to the effects of respiration, which is 
advantgeous for the HA environment where hypoxia and hyperventilation is typical.24-26 The ithlete HRV score has been shown to provide good to excellent agreement with the RMSSD obtained from a standard five minute electrocardiographic recording at sea level and more recently at HA. 25,27

The aim of this study was to investigate, for the first time, the practical use of the ithelte HRV monitor as a way of monitoring acclimatisation to HA and the onset of AMS.

\section{METHODS}

\section{Subjects}

Healthy British Military service personnel aged >18years were included. Health status was confirmed following a detailed baseline health questionnaire. All subjects had to be in date with their fitness assessments including the military fitness standard for a 1.5 mile run. Key exclusion criteria included subjects with any history of cardiac arrhythmias or need for either rate or rhythm controlling medications. All subjects lived at low altitude and none had prior exposure to $>1400 \mathrm{~m}$ terrestrial altitude in the four weeks prior to this study.

Data collection took place during a trek to Dhaulagiri base camp (western Nepal). Subjects were all part of the British Services Dhaulagiri Medical Research Expedition. After arriving at Kathmandu at $1400 \mathrm{~m}$, the subjects travelled by road to $890 \mathrm{~m}$, then $2650 \mathrm{~m}$ before commencing the ascent on foot to 5140m (over Dhamphus Pass, 5240m) over 10 days (figure 1).

\section{Recording of Heart Rate variability (HRV)}

HRV was recorded at approximately 0700 each morning using a finger sensor and linked smartphone via the ithlete ${ }^{\mathrm{TM}}$ app (HRV Fit Ltd. Southampton, UK) as previously described and validated.25,27 All participants were studied post micturition but prior to breakfast or caffeine. All subjects were seated, wearing warm clothing in either a tent or building. All subjects were encouraged to rest for at least five minutes before the HRV recordings were obtained. The ithelte ${ }^{\mathrm{TM}}$ acquires a 55 second recording with visual breathing prompts to regulate the rate of both inspiration and expiration in order to standardise the HRV measurements. The ithlete ${ }^{\mathrm{TM}}$ modifies the acquired RMSSD by taking the natural log transformation and multiplying by twenty $(\operatorname{lnRMSSD} \times 20)$ to provide a more interpretable HRV score for the user on a $\sim 100$ point scale.23 It has a patented algorithm for the exclusion of both artifacts and ectopic beats whereby R-R (P-P) intervals of $<500 \mathrm{~ms}$ or $>2000 \mathrm{~ms}$ are excluded as are abnormal adjacent R$\mathrm{R}$ intervals whose difference significantly exceeds the mean R-R interval.28

\section{Acute mountain sickness (AMS) scores}

Measurement of AMS was undertaken at the same time that HRV assessments were performed using the Lake Louis Scoring System (LLS).29,30 A total score of $>3$ in the presence of headache was used to diagnose AMS and a score >5was considered consistent with severe AMS.29-31

\section{Physiological measurements}

Oxygen saturations $\left(\mathrm{SpO}_{2}\right)$ and heart rate were measured using a Nonin Onyx (Nonin Medical Inc, Plymouth, Minnesota) pulse oximeter just prior to the assessment of HRV.

\section{Ethics}

The study was approved by the Ministry of Defence Research Ethics Committee and complied with the standards set in the Declaration of Helsinki. All subjects gave written informed consent.

\section{Statistical analysis}


Statistical calculations and figures were performed using GraphPad Instat and GraphPad Prism version 4.00 for Windows. Normality of continuous data was assessed following inspection and the Kolmogorov-Smirnov statistic. All continuous data are presented as the mean \pm standard deviation. Independent two group comparisons of continuous data were analysed using an unpaired $t$ test or Man Whitney test for parametric and non-parametric data respectively. Comparisons of continuous data from $>3$ groups of parametric and on parametric data were performed using a one-way ANOVA or Kruskal-Wallis test respectively. The effect size $(n)$ for any potential changes in HRV with HA was also calculated as the sum of squares for between-treatment effects divided by the total sum of squares. Correlation analyses were performed using Pearson Correlation and Spearman's rank correlation with 95\% confidence intervals depending on data normality. Receiver operating characteristic (ROC) curves were constructed to assess the sensitivity and specificity of the ithlete ${ }^{\mathrm{TM}}$ and the area under the curve (AUC) for the HRV score to accurately identify subjects with AMS was determined. A p value of $<0.05$ was considered significant for all comparisons.

\section{RESULTS}

Twenty one subjects (20 men, 1 woman) aged 36.2 \pm 6.9 (years were studied over their first 13 days in Nepal (table 1). Seventeen subjects reached 5140m on day 11, two on day 13 and two beyond the study period. There was a significant fall in $\mathrm{SpO}_{2}$ and increase in resting heart rate with gains in HA (Table 2). There was also an overall increase in LLS at HA (table 2) compared with the values at $890 \mathrm{~m}$. Successful ithleteтм recordings were possible in $93 \%$ of cases. AMS occurred in 11 subjects $(52.4 \%)$ and all at an altitude of $>2650 \mathrm{~m}$. There was a weak but significant correlation between HRV score and $\mathrm{SpO}_{2} \mathrm{r}=0.16$; 95\% CI $0.02-0.29$ : $\mathrm{p}=0.02$ ). HRV inversely correlated with LLS Scores $(\mathrm{r}=-0.26 ;-0.38$ to $-0.13: \mathrm{p}<0.001)$. There was a moderate inverse correlation between the HRV score and heart rate $(\mathrm{r}=-0.41 ;-0.52$ to 0.30 : $\mathrm{p}<0.0001)$.

\section{HRV and acute Mountain Sickness}

There was a non-significant trend to reducing HRV score with increasing HA ( $n_{2}$ 0.042; $\mathrm{p}=0.09$ ) (table 2 and figure 2). However, this fall was significant at $3700 \mathrm{~m}, 4100 \mathrm{~m}$ and $5140 \mathrm{~m}$ versus $890 \mathrm{~m}$. The HRV score fell with increasing AMS Scores (ANOVA $n_{2}=0.043 ; \mathrm{p}=0.007$ ) (figure 3), but this difference was only significant on post-test between those with a LLS of 0 versus those with a LLS $>5$. HRV scores were significantly lower in those with AMS (mild and severe combined) $67.9 \pm 13.1$ vs those without AMS 77.5 $\pm 13.1(\mathrm{p}=0.002)$. HRV scores significantly fell from $77.5 \pm 13.1$ for those with no AMS to $69.7 \pm 14.0$ with mild AMS and $67.1 \pm 13.1$ with severe AMS ( $\mathrm{p}=0.007$, figure 4), however the difference was only significant between those without AMS and those with severe (not mild) AMS on post-test.

The HRV score was very marginally better at distinguishing severe AMS versus those without severe AMS (ROC curve $0.74 ; 95 \%$ CI 0.58 to $0.89: \mathrm{p}=0.006$ ) than differentiating all AMS (mild and severe combined) from no AMS (area under the curve [AUC] 0.71: 95\% CI 0.58 to 0.84; $\mathrm{p}=0.002$ ) (figure 5). An HRV score of $<76$ had a sensitivity of $83 \%$ and a specificity of $53 \%$ for the correct identification of severe AMS at a likelihood ration of 1.80 (figure 5). However, the change (delta) in the ithlete ${ }^{\mathrm{TM}} \mathrm{HRV}$ Score (compared with baseline at $1400 \mathrm{~m}$ ) was a better predictor of severe AMS (AUC 0.80; 95\% CI 0.70 to $0.90 ; \mathrm{p}=0.0004$ ) (figure 6). A fall in the HRV score of $>6$ points compared had a sensitivity of $83 \%$ and specificity of $60 \%$ to identify severe AMS (likelihood ration 1.9) (figure 6). There was no difference in the HRV 
scores at $1400 \mathrm{~m}$ between those who did or did not develop severe or any AMS at higher altitudes.

\section{DISCUSSION}

This is the first study, to the author's knowledge, to investigate the link between AMS and HRV at HA to 5140m using a portable smart phone HRV device (ithleteтм). The ithleteтм HRV Score inversely correlated with the LLS but was a relatively weak discriminator for the identification of AMS and its severity. However, a fall in the HRV score, at HA versus baseline, of $>6$ versus baseline was a moderate albeit non-specific marker of severe AMS.

There is an increasing body of research that has shown that HA exposure leads to a reduction in HRV. This is thought to relate to a significant increase in sympathetic and a decrease in parasympathetic tone.17,18,22 With acclimatization there appears to be progressive shift toward a higher parasympathetic tone.31 Much less is known about the link between HRV and AMS. There is data to suggest that changes in HRV are linked to the AMS susceptibility and development.19,22 but also data to the contrary challenging refuting this the link.20,21 This conflicting data may be partly explained by the marked differences in the design, ascent profile and the methods of HRV recording across the studies. Karinen et al studied 36 climbers on four different expeditions and three differing ascents. The authors found that those with a lower HRV (RMSSD2min and HF [high frequency] 2 min from a five minute HRV recording) at $2400 \mathrm{~m}$ predicted those who later developed AMS at moderate altitudes (3000-4300m).22 Huang et al study 32 patients over a progressive HA trek to $3440 \mathrm{~m}$. They noted that those with both (high frequency) $\mathrm{HF} \%<20 \%$ (suggesting reduced parasympathetic tone) and low frequency: high frequency (LF:HF) ratio > 1.3 (increased sympathetic balance) measured at $1317 \mathrm{~m}$ had an odds ratios of $7.00(\mathrm{p}=0.047$ ) for the subsequent development of develop AMS at $3440 \mathrm{~m}$ (Huang 2013).19 The authors did not report data on the RMSSD. In our study whilst we did observe significantly lower ithleteтм HRV (RMSSD) scores in those with AMS and more severe AMS, lower altitude HRV scores failed to predict AMS development at HA. Furthermore the effect size for change in HRV with worsening AMS severity was modest.

One of the major additional confounders in all of these studies examining the relationship of HRV to symptom of AMS has been in the definition of AMS itself. The diagnosis of AMS is made using a self-reported questionnaire based assessment, most notably the LLS and is highly subjective and therefore likely to be influenced by a subjects' expectations or aspirations and it can be a relatively poor predictor of illness.33,34 For example, in a previous study of 248 healthy adults travelling to $3200 \mathrm{~m}$ Bartsch has noted that only $61 \%$ of the mountaineers reporting a LLS $>5$ actually said they felt ill.35 Hence, a more reproducible and objective measure of HA- related illness would be welcome. The rational for using HRV to improve the detection of AMS is strong. Whilst the underlying pathophysiology of AMS is still poorly understood current evidence suggests that it involves vasogenic cerebral oedema secondary to hypoxia-induced sympathetic activation.1 The normal physiological diuresis at HA, which acts to reduce plasma volume and increase in haematocrit (to improve tissue oxygenation), is also affected leading to a reduced water clearance and a positive net water balance. 36 Changes in plasma volume which is integral to the HA acclimatisation and AMS development are strongly influenced by alterations in parasympathetic tone. $37 \mathrm{HRV}$ is also heavily afeected by a number of other autonomic stressors such as fitness levels, physical fatigue, cold and exertion which important factors at HA and are known to be contributory factors to AMS development and progression. 38 
One of the greatest clinical applications of the ithleteTM and other HRV measures is in the detection of overtraining which shares many features in common with AMS. Hence further studies examining the utility of HRV to monitor recovery from exercise at HA and to tailor individuals' acclimatisation, rather than relying on guidelines such as $300 \mathrm{~m}$ ascent per day, would be welcome. The ithleteтм is currently marketed with a visual display of other domains such as sleep, fatigue, irritability and muscle soreness which could be potentially adapted to give a scale related to the LLS and is an area worthy of further research.

This study has a number of limitations and strengths that need to be acknowledged. The ambient temperature varied throughout the study and the HRV measurements were performed in tents above $1400 \mathrm{~m}$. It is well known that change in both environment and temperature can influence HRV and due to the nature of this study it was not possible to adjust for these factors.38 In this study we used a finger probe rather than a blue tooth chest strap sensor to acquire heart beat data and successful data recording was not possible in $7 \%$ which could have influenced the findings. The ithleteтм only provides a single measure of HRV from a very short recording time. Hence, we do not know whether our findings would be different if another HRV platform and a five-minute recording period with a wider array of HRV data outputs include frequency domain analyses were used. The ithleteтм HRV score is related the RMSSD and is considered a marker of relative parasympathetic activity and does not assess sympathetic tone or the sympathetic/parasympathetic balance provided by more sophisticated devices. However, the aim of this study was to assess the utility of a simple, inexpensive, portable and user friendly deice that is widely available to potentially predict HA related illness and hence maximising the clinical impact of a potentially strongly positive finding. The key strengths of this study was that all subjects underwent the same exercise, diet and acclimatisation protocol and the altitude achieved was significant and greater than the majority of published HRV studies at HA.

In summary this is the first paper to show a practical application of a simple measure of HRV to provide an objective measure of severe AMS. A fall in the ithleteтм HRV score of $>6$ points from baseline had moderate precision for the detection of severe AMS.

\section{REFERENCES}

1. Richalet JP, Canouï-Poitrine F, Larmignat P. Acute high-altitude illnesses. $N$ Engl $J$ Med 2013; 369:1664-5.

2. Waeber B, Kayser B, Dumont L, Lysakowski C, Tramèr MR, Elia N. Impact of Study Design on Reported Incidences of Acute Mountain Sickness: A Systematic Review. High Alt Med Biol 2015; 16:204-15.

3. Karinen HM, Peltonen JE, Kähönen M, Tikkanen HO. Prediction of acute mountain sickness by monitoring arterial oxygen saturation during ascent. High Alt Med Biol 2010; 11:325-32.

4. Maggiorini M, Bühler B, Walter M, Oelz O. Prevalence of acute mountain sickness in the Swiss Alps. BMJ 1990; 301:853-5.

5. Mazzeo RS. Altitude, exercise and immune function. Exerc Immunol Rev 2005;11:616.

6. Ainslie PN, Lucas SJ, Fan JL et al. Influence of sympathoexcitation at high altitude on cerebrovascular function and ventilatory control in humans. J Appl Physiol (1985) 2012;113:1058-67.

7. Richalet JP.Physiological and Clinical Implications of Adrenergic Pathways at High Altitude. Adv Exp Med Biol 2016;903:343-56. 
8. Kamimori GH, Ryan EJ, Otterstetter R, Barkley JE, Glickman EL, Davis HQ. Catecholamine levels in hypoxia-lnduced acute mountain sickness. Aviat Space Environ Med 2009;80:376-80

9. Loeppky JA, Icenogle MV, Maes D, Riboni K, Scotto P, Roach RC. Body temperature, autonomic responses, and acute mountain sickness. High Alt Med Biol 2003;4:367-73.

10. Lanfranchi PA, Colombo R, Cremona G, Baderna P, Spagnolatti L, Mazzuero G, Wagner P, Perini L, Wagner H, Cavallaro C, Giannuzzi P: Autonomic cardiovascular regulation in subjects with acute mountain sickness. Am J Physiol Heart Circ Physiol 2005, 289:H2364-H2372.

11. Koyama S, Kobayashi T, Kubo K, et al. The increased sympathoadrenal activity in patients with high altitude pulmonary edema is centrally mediated. Jpn J Med 1988;27:10-6.

12. Weimer LH Autonomic testing: common techniques and clinical applications. Neurologist 2010; 16:215-22.

13. Lahiri MK, Kannankeril PJ, Goldberger JJ. Assessment of autonomic function in cardiovascular disease: physiological basis and prognostic implications. J Am Coll Cardiol 2008; 51:1725-33

14. Kiviniemi AM, Tulppo MP, Hautala AJ, Vanninen E, Uusitalo AL. Altered relationship between R-R interval and R-R interval variability in endurance athletes with overtraining syndrome. Scand J Med Sci Sports 2014; $24: \mathrm{e} 77$.

15. Sassi R, Cerutti S, Lombardi F et al. Advances in heart rate variability signal analysis: joint position statement by the e-Cardiology ESC Working Group and the European Heart Rhythm Association co-endorsed by the Asia Pacific Heart Rhythm Society. Europace 2015;17:1341-53.

16. Sevre K, Bendz B, Hankø E et al. Reduced autonomic activity during stepwise exposure to high altitude. Acta Physiol Scand 2001;173:409-17.

17. Wille M, Mairer K, Gatterer H, Philippe M, Faulhaber M, Burtscher M. Changes in cardiac autonomic activity during a passive 8 hour acute exposure to $5500 \mathrm{~m}$ normobaric hypoxia are not related to the development of acute mountain sickness. Int J Sports Med 2012;33:186-91.

18. Huang HH, Tseng CY, Fan JS et al. Alternations of heart rate variability at lower altitude in the predication of trekkers with acute mountain sickness at high altitude. Clin J Sport Med 2010 ;20:58-63.

19. Koehle MS, Guenette JA, Warburton DE. Oximetry, heart rate variability, and the diagnosis of mild-to-moderate acute mountain sickness. Eur J Emerg Med 2010;17:119-22.

20. Buchheit M, Simpson BM, Schmidt WF et al. Predicting sickness during a 2-week soccer camp at 3600 m (ISA3600). Br J Sports Med 2013;47 Suppl 1:i124-7.

21. Karinen HM, Uusitalo A, Vähä-Ypyä H et al. Heart rate variability changes at $2400 \mathrm{~m}$ altitude predicts acute mountain sickness on further ascent at $3000-4300 \mathrm{~m}$ altitudes.

Front Physiol 2012; 30; 3:336.

22. Heart rate variability: standards of measurement, physiological interpretation and clinical use. Task Force of the European Society of Cardiology and the North American Society of Pacing and Electrophysiology. Circulation 1996; 93:1043-65. 23. Wegerif SC. U.S. Patent Application (2009); 12/565,717.

24. Esco MR, Flatt AA. Ultra-Short-Term Heart Rate Variability Indexes at Rest and Post-Exercise in Athletes: Evaluating the Agreement with Accepted

Recommendations. Journal of Sports Science and Medicine 2014; 13:535 - 541.

25. Flatt AA, Esco MR. Heart rate variability stabilization in athletes: towards more 
convenient data acquisition. Clin Physiol Funct Imaging 2016;36:331-6.

26. Penttilä J, Helminen A, Jartti T, Kuusela T, Huikuri HV, Tulppo MP, Coffeng R,

Scheinin H. Time domain, geometrical and frequency domain analysis of cardiac vagal outflow: effects of various respiratory patterns. Clin Physiol 2001;21:365-76. 27. Boos CJ, Bakker-Dyos J, Watchorn J, Woods DR et al. A comparison of two methods of heart rate variability assessment at high altitude. Clin Physiol Funct Imaging. 2016 Jan 14. doi: 10.1111/cpf.12334. [Epub ahead of print].

28. Wegerif SC. Method, system and software product for the measurement of heart rate variability. US Patent 8666482 B2 / 12/565,717; 4th May 2014:

https://www.google.co.uk/patents/US8666482

29. Hackett, P.H. \& Oelz, O (1992) The Lake Louise consensus on the quantification of altitude illness. In: Sutton JR, Houston CS \& Coates G (eds) Hypoxia and Mountain Medicine: Queen City Printers, Burlington, VT: 327-330.

30. Roach RC, Bärtsch P, Oelz O et al. The Lake Louise acute mountain sickness scoring system. In: Hypoxia and Molecular Medicine. Burlington, VT: Queens City Press $1993 ; 272-274$.

31. Woods DR, Begley J, Stacey M et al. Severe acute mountain sickness, brain natriuretic peptide and NT-proBNP in humans Acta Physiol 2012; 205: 349-55.

32. Bhaumik G, Dass D, Bhattacharyya D, Sharma YK, Singh SB. Heart rate variabilty changes during first week of acclimatization to $3500 \mathrm{~m}$ altitude in Indian military personnel. Indian J Physiol Pharmacol 2013;57:16-22.

33. Dellasanta P, Gaillard S, Loutan L, Kayser B. Comparing questionnaires for the assessment of acute mountain sickness. High Alt Med Biol 20071;8:184-91.

34. Harrison MF, Anderson PJ, Johnson JB, Richert M, Miller AD, Johnson BD.Acute

Mountain Sickness Symptom Severity at the South Pole: The Influence of Self-

Selected Prophylaxis with Acetazolamide. PLoS One 2016;11:e0148206.

35. Bartsch P, Bailey DM, Berger MM, Knauth M, Baumgartner RW. Acute Mountain

Sickness: controversies and advances. High Alt Med Biol 2004; 5:110-24.

36. Gatterer H, Wille M, Faulhaber M, Lukaski H, Melmer A, Ebenbichler C, Burtscher

M. Association between body water status and acute mountain sickness. PLoS One 2013;8e73185.

37. Buchheit M, Laursen PB, Al Haddad H, Ahmaidi S. Exercise-induced plasma volume expansion and post-exercise parasympathetic reactivation. Eur J Appl Physiol 2009;105:471-81.

38. Mäkinen TM, Mäntysaari M, Pääkkönen T et al. Autonomic nervous function during whole-body cold exposure before and after cold acclimation. Aviat Space Environ Med $2008 ; 79: 875-82$. 
Table 1: Baseline Demographics

\begin{tabular}{ll}
\hline Demographic & Result \\
\hline Number & 21 \\
Age, years (range) & $36 . .2 \pm 6.5(26-48)$ \\
Males $\mathrm{n}, \%$ & $20(95.2 \%)$ \\
Height, cm & $177.3 \pm 7.9$ \\
Weight, $\mathrm{kg} / \mathrm{m}^{2}$ & $76.2 \pm 8.7$ \\
Heart rate/ minute & $59.7 \pm 12.0$ \\
Systolic blood pressure & $134.3 \pm 12.3$ \\
Diastolic blood pressure & $80.0 \pm 8.4$ \\
Body mass index kg/m ${ }^{2}$ & $24.2 \pm 2.0$ \\
Ethnicity, $\%$ & \\
- Caucasian & $53.5 \%$ \\
Smoking status $(\mathrm{N}, \%)$ & $100 \%$ \\
- Current & \\
- Ex & \\
- Never & \\
\hline
\end{tabular}


Table 1. Effect of High Altitude on Physiological measurements, Lake Louise Scores for Acute Mountain Sickness and Heart Rate Variability

\begin{tabular}{llllllll}
\hline & $1400 \mathrm{~m}$ & $890 \mathrm{~m}$ & $\mathbf{2 6 5 0 \mathrm { m }}$ & $3700 \mathrm{~m}$ & $4100 \mathrm{~m}$ & $\mathbf{5 1 4 0 \mathrm { m }}$ & P Value \\
\hline $\mathrm{SpO}_{2} \%$ & $96.6 \pm 1.4$ & $96.9 \pm 1.7$ & $94.3 \pm 2.2$ & $88.8 \pm 3.4$ & $88.0 \pm 3.4$ & $79.3 \pm 5.7$ & $<0.001^{\text {bat }}$ \\
Heart rate, & $62.3 \pm 10.5$ & $60.9 \pm 9.6$ & $64.1 \pm 11.4$ & $70.8 \pm 10.7$ & $76.0 \pm 10.4$ & $79.5 \pm 11.6$ & $<0.001^{\text {bad }}$ \\
beats/min & & & & & & & \\
LLS & $0.4 \pm 0.7$ & $0.3 \pm 0.7$ & $2.2 \pm 5.5$ & $1.3 \pm 2.1$ & $1.1 \pm 2.5$ & $1.8 \pm 2.9$ & $0.04 \mathrm{~b}$ \\
(range) & $(0-2)$ & $(0-2)$ & $(0-23)$ & $(0-9)$ & $(0-16)$ & $(0-15)$ & \\
HRV Score & $79.6 \pm 14.5$ & $82.8 \pm 13.0$ & $78.7 \pm 13.1$ & $74.3 \pm 14.6^{*}$ & $74.5 \pm 12.4^{*}$ & $76.0 \pm 12.5^{*}$ & 0.09
\end{tabular}

LLS, Lake Louis Score for Acute Mountain Sickness; HRV Heart Rate Variability; * significant (p<0.05)

differences in unpaired test vs $890 \mathrm{~m}$; a $1400 \mathrm{~m}$ vs $890 \mathrm{~m}$, b $2650 \mathrm{~m}$ vs $890 \mathrm{~m}, \mathrm{c} 3700 \mathrm{~m}$ vs $890 \mathrm{~m}, \mathrm{~d} 4100 \mathrm{~m}$ vs $890 \mathrm{~m}$.

e $5140 \mathrm{~m}$ vs $890 \mathrm{~m}$

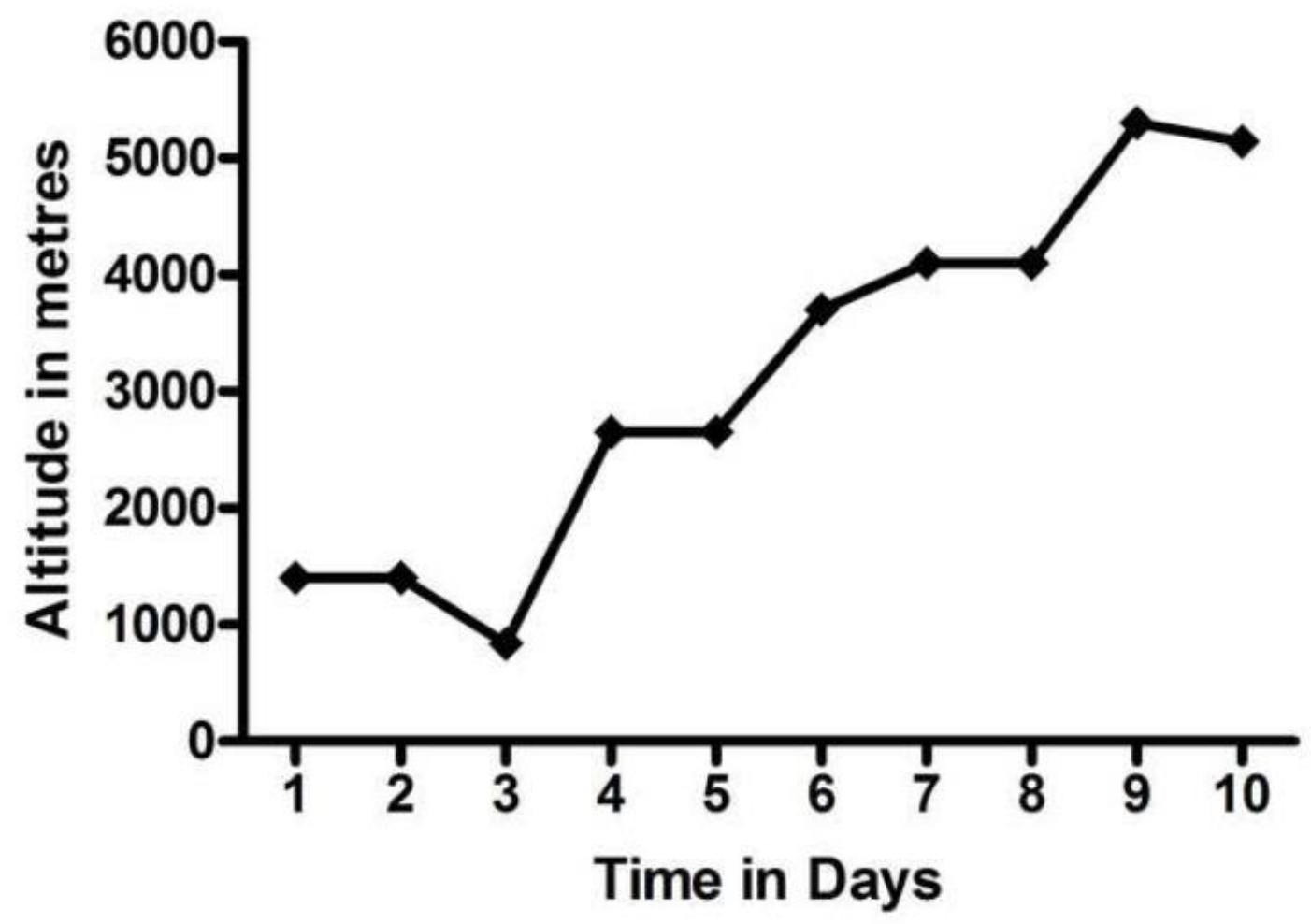

Figure 1 Ascent profile 


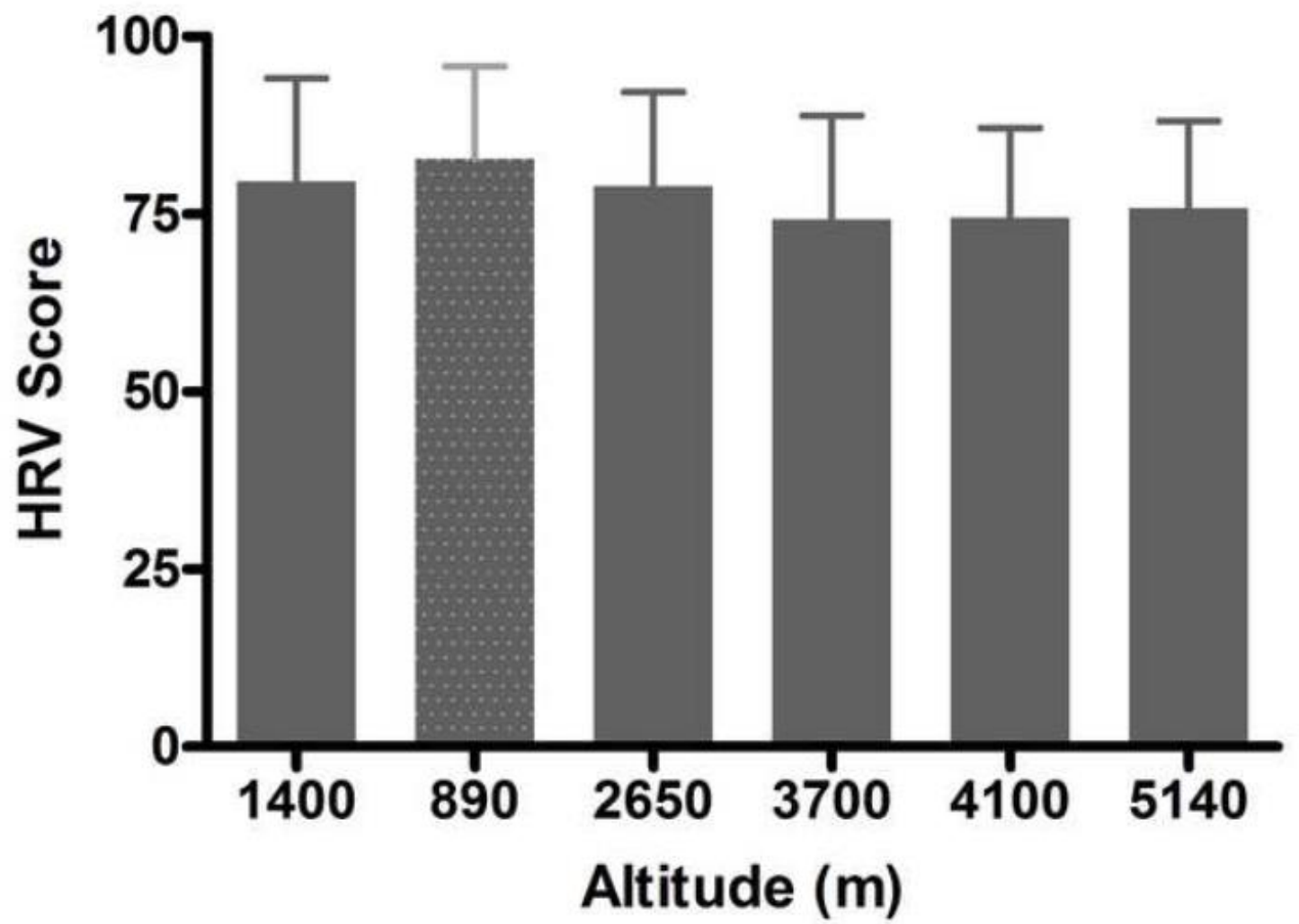

Figure 2 Changes in ithleteтм Heart Rate Variability Score with increases in altitude 


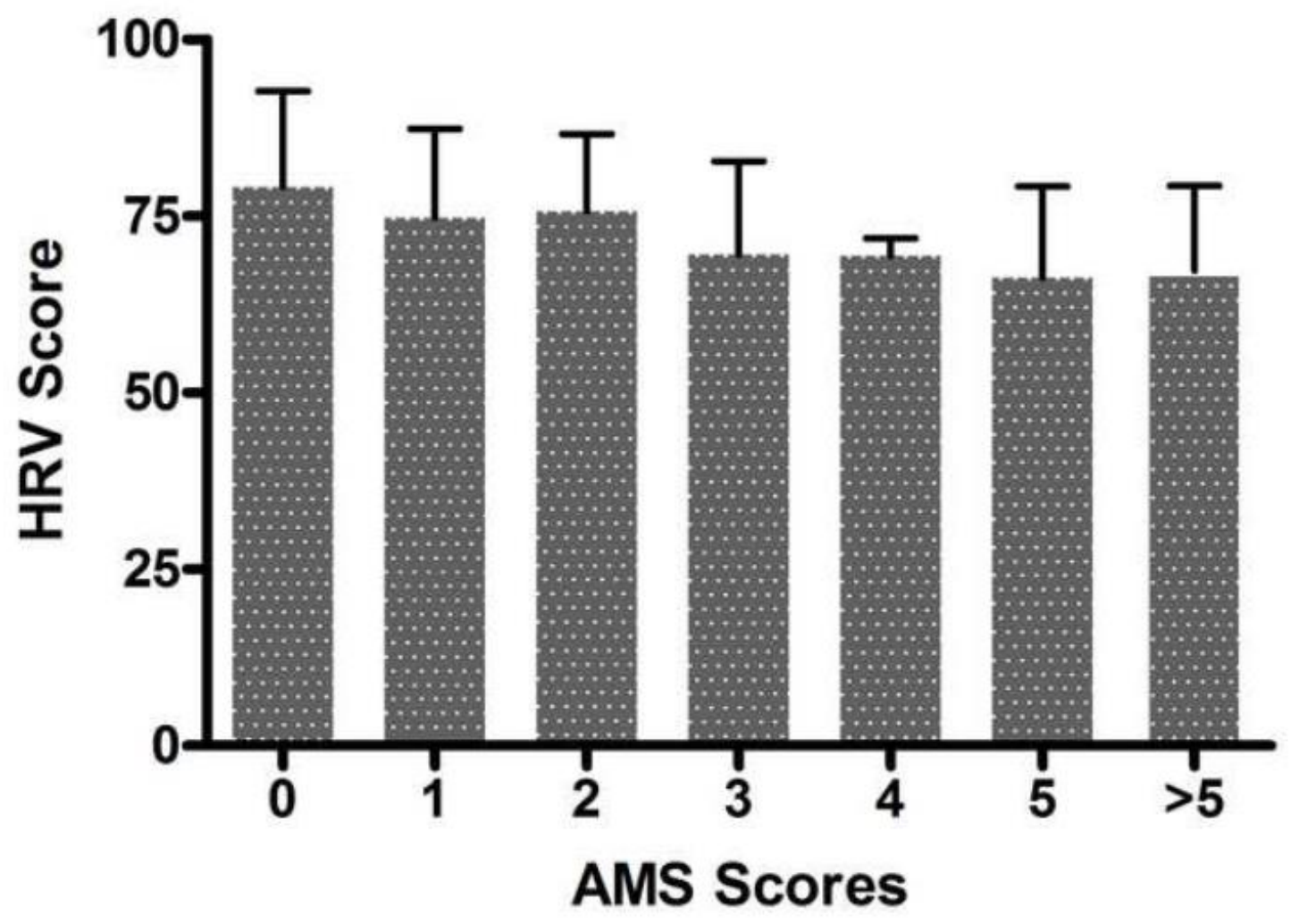

Figure 3 Changes in Heart Rate Variability with Acute Mountain Sickness Scores (LLS) 


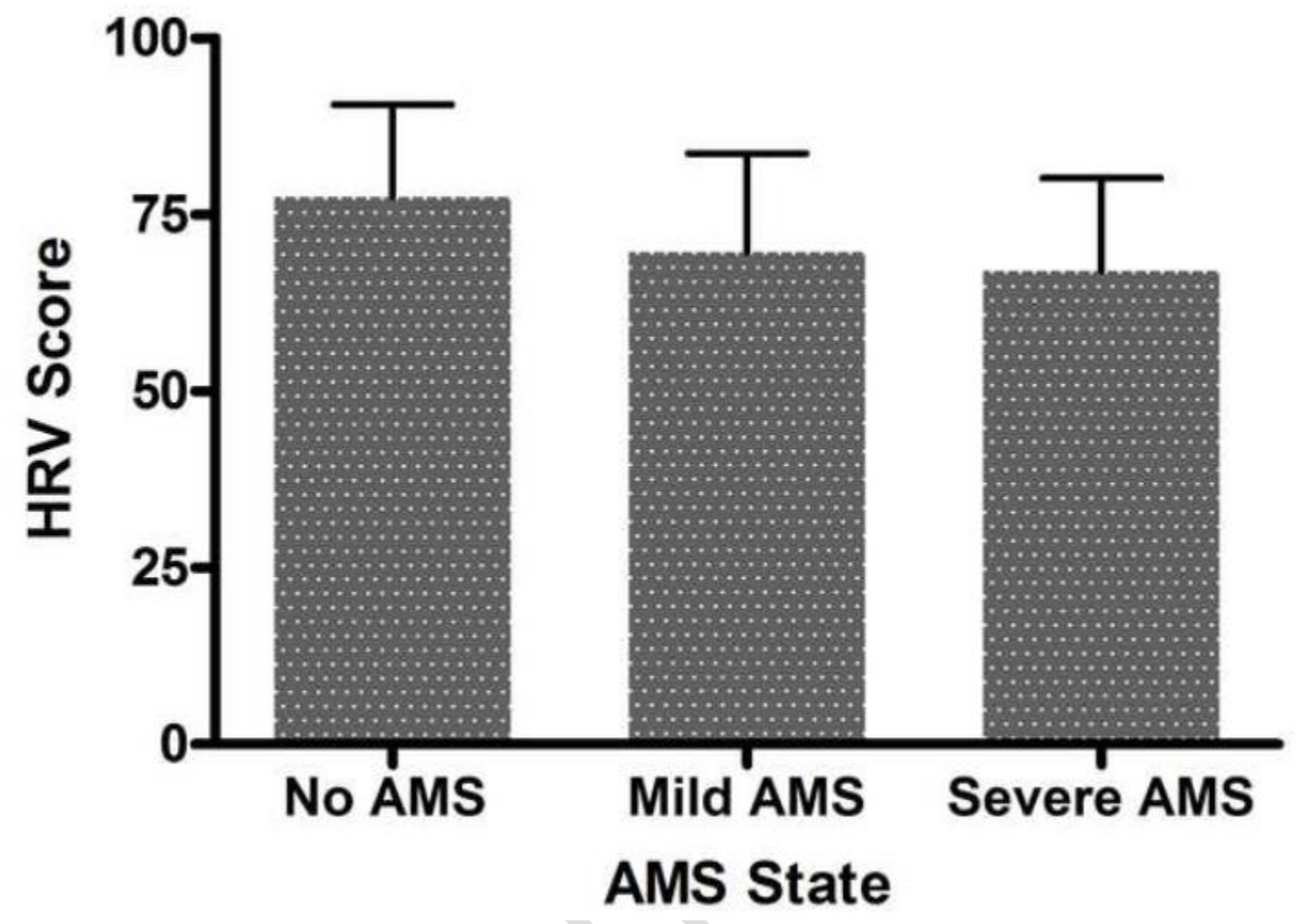

Figure 4 Acute Mountain Sickness Severity and ithleteтм Heart Rate Variability Scores 


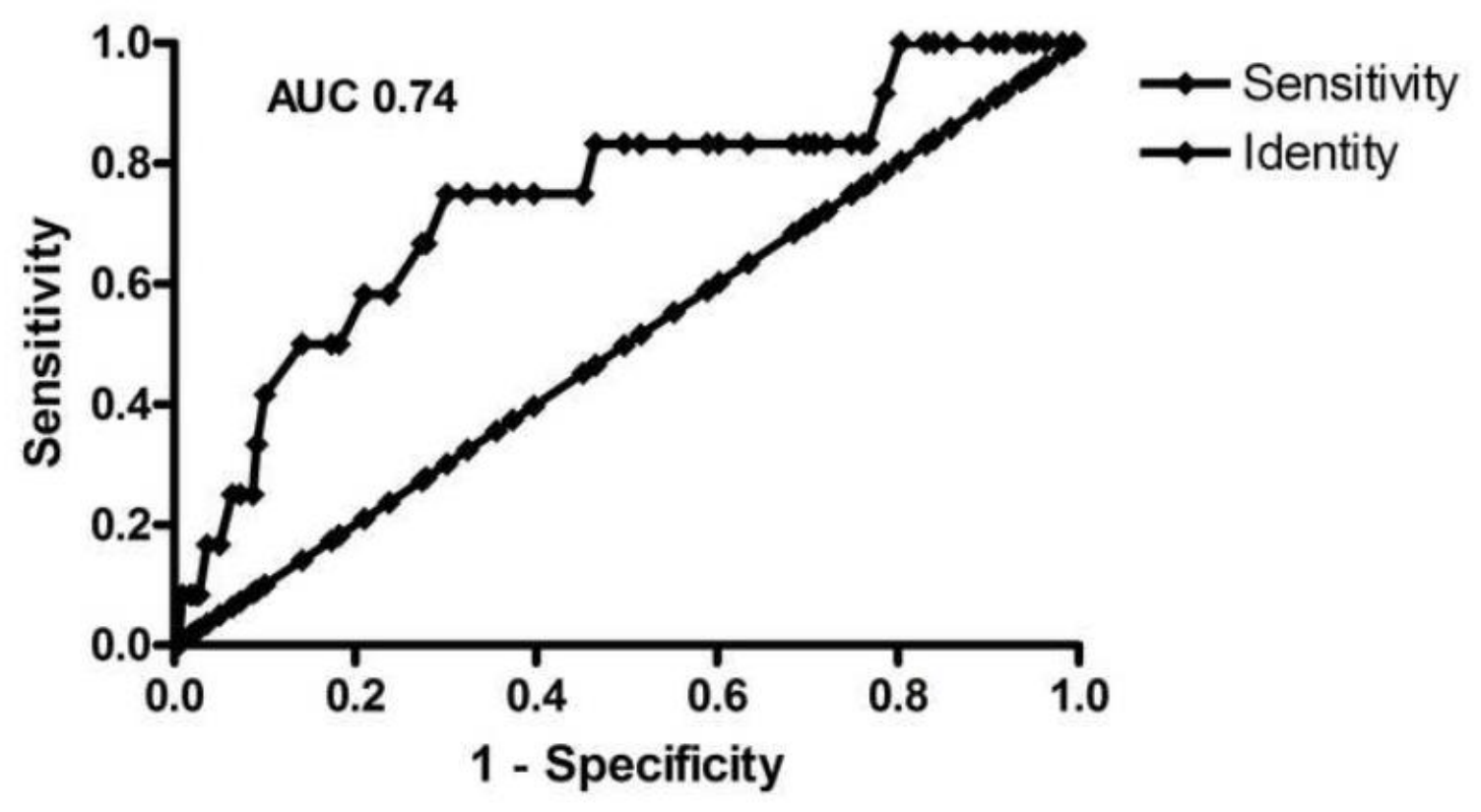

Figure 5 Receiver operating characteristic (ROC) Curve for Heart Rate Variability score for Detection of severe Acute Mountain Sickness

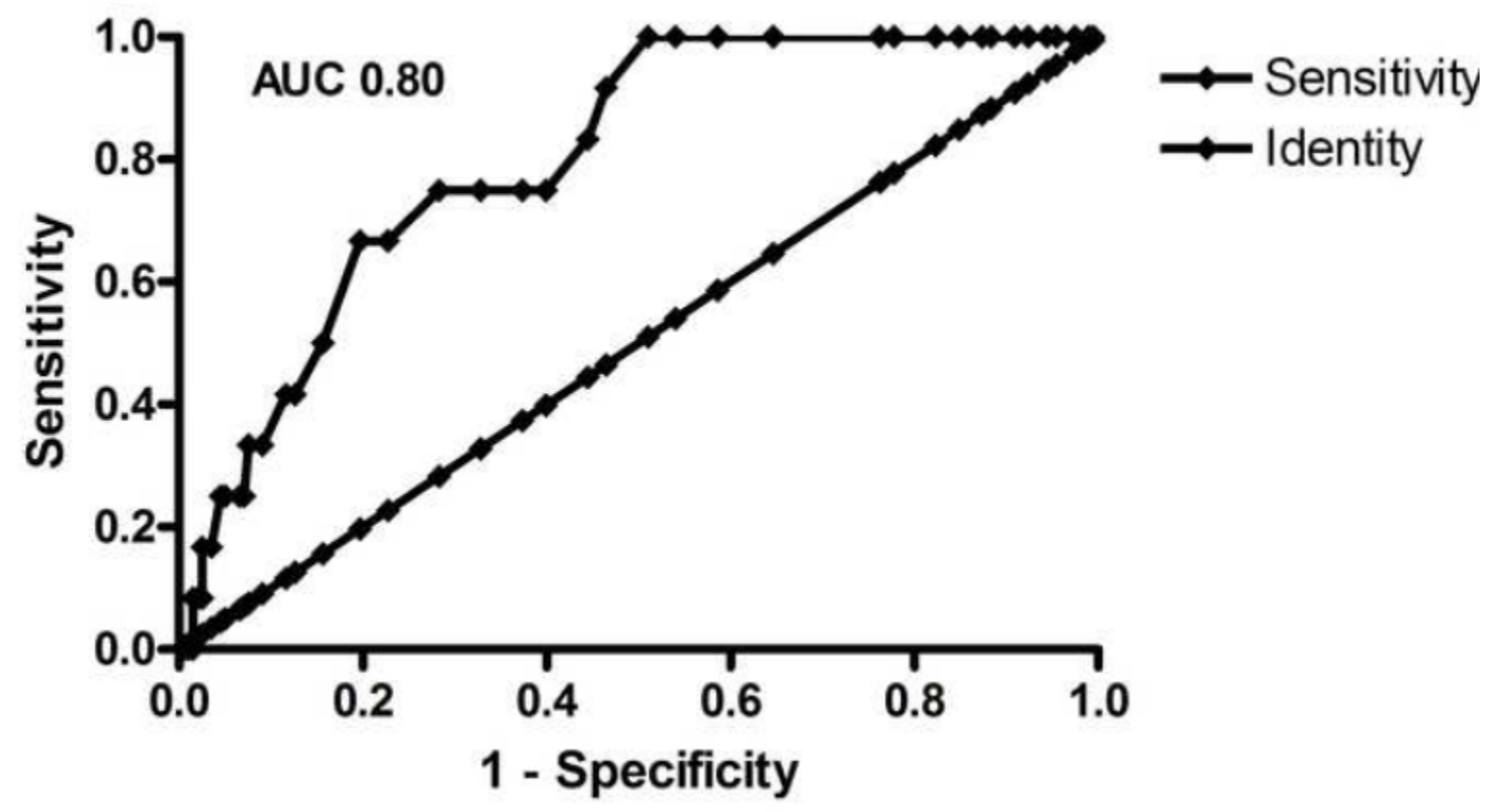

Figure 6 Receiver operating characteristic (ROC) Curve for change in Heart Rate Variability score and identification of severe Acute Mountain Sickness 